\title{
Smart Grid Distribution Management System (SGDMS) for Optimised Electricity Bills
}

\author{
Weixian Li, Chonghao Ng, Thillainathan Logenthiran, Van-Tung Phan, Wai Lok Woo \\ School of Electrical and Electronic Engineering, Newcastle University, Singapore Campus, Singapore \\ Email: w.li17@newcastle.ac.uk, c.h.ng@newcastle.ac.uk, t.logenthiran@ncl.ac.uk, vantung.phan@ncl.ac.uk, \\ lok.woo@newcastle.ac.uk
}

How to cite this paper: Li, W.X., Ng, C.H. Logenthiran, T., Phan, V.-T. and Woo, W.L. (2018) Smart Grid Distribution Management System (SGDMS) for Optimised Electricity Bills. Journal of Power and Energy Engineering, 6, 49-62.

https://doi.org/10.4236/jpee.2018.68003

Received: June 30, 2018

Accepted: August 17, 2018

Published: August 20, 2018

Copyright $\odot 2018$ by authors and Scientific Research Publishing Inc. This work is licensed under the Creative Commons Attribution-NonCommercial International License (CC BY-NC 4.0). http://creativecommons.org/licenses/by-nc/4.0/

\section{(c) (i) (8) Open Access}

\begin{abstract}
This paper presents the use of proposed Smart Grid Distribution Management System (SGDMS) for Singapore contestable and non-contestable consumers. The SGDMS is a distributed management system proposed using Multi-Agent System (MAS) technology. This system can optimise the distribution of renewable energy while minimizing electricity bills for consumers. The entire system was developed using Java with the extension of JADE which is an IEEE FIPA compliant multi-agent system platform. This decentralised platform allows agents to interact and communicate using energy sources from different sectors and control them intelligently to minimise the cost of electricity for the consumers. Simulation studies were carried out on the proposed system to show its potential for providing solutions through intelligent distribution techniques and how it influences the cost of electricity.
\end{abstract}

\section{Keywords}

Smart Grid, Multi-Agent System, Electricity Bill

\section{Introduction}

Power grid system is one of the main factors which control the distribution of the electricity to various grids. Tradition power grid is usually dispatchable and relatively inexpensive, however, it will cause significant pollution to the environment. As such, renewable energy has been extensively researched due to the generation of clean power sources. However, the generation of power cannot be accurately predicted. Hence, smart grid system is more favourable compared to traditional power grid [1].

In order to achieve a low carbon energy environment, power grids and renewable energy integration developments are currently carried out. However, 
the increasing research on such technology would incur a high cost which requires the support of the government [2] [3] [4] [5].

The world renewable energy has been contributing $19 \%$ to the current electricity usage. Hydroelectric energy had been producing $16 \%$, thus making wind and PV energy production modest, but it means that many initiatives can improve these renewable energies [6] [7].

Renewable energy systems (RES) are not able to replace existing electrical grids as it has been established and used for ages due to its reliability. Although RES technology is not able to cope with the demand of electricity consumption these days, integrating it with the existing power grid has shown that it is able to change the system towards certain extent [8] [9].

RES involves certain criteria to be practical. The criteria are reliability, efficiency, development of algorithms for advanced control, and monitoring. Therefore, availability of equipment or tools would be crucial for the research of such technology [10]. The use of RES was encouraged by various countries to decarbonise the traditional power generators. This resulted in increasing use of wind, tidal, and solar to produce distributed power for the grid with immense pace.

Ng, C. H., et al. [11] proposed an intelligent distributed smart grid network using reconfiguration to perform self healing on a mesh transmission network. This proposed method uses a set of rules and search techniques to solve sudden abnormal situations in the grid. However, it did not consider the cost of electricity despite solving anomaly situations.

W. Li., et al. [12] proposed an intelligent multi-agent system for power grid communication. This proposed method introduces MAS to enhance the data communication in existing power grid for efficient power distribution. However, except the enhancement of data communication, it did not include any algorithms for optimising the power distributions and reducing electricity cost. Thus, these studies show the need of algorithms to reduce the cost of electricity in the power grid with enhanced communication channel.

The proposed Smart Grid Distribution Management System (SGDMS) allows smart grid to be equipped with better distribution techniques to optimise electricity costs. Additionally, the proposed system includes MAS as its communication channel that increases the reliability and efficiency of data transmission.

The remaining paper is organised as follows: Section 2 shares the information used for the proposed system. Section 3 shows the proposed SGDMS. Section 4 provides simulation results. Finally, the paper is concluded in Section 5.

\section{Information on Power Grid in Singapore}

Singapore power grid was distributed to 3 main sub-grids which are the industrial, commercial, and residential grids. Transport-related and others grids contain a smaller distribution of electricity. Singapore is exploring the options of 
alternative power resources using renewable energy to create a smart nation concept of a green country.

Singapore power grid has one of the most reliable electricity networks in the world. The grid had already deployed advanced Supervisory Control and Data Acquisition (SCADA) systems which were able to read electricity supply data to bring its power grid capabilities even further.

In Singapore, the Energy Market Authority (EMA) was set up to liberalise the electricity markets to promote reliable, secure, and effective electric supply. Energy Market Company (EMC) was established to connect the electricity makers and buyers in order to give alternative from regulated tariffs from SP Services [13]. The wholesale electricity market allows the consumer to purchase electricity from the electricity retailers that fluctuates every half an hour. Currently, in Singapore, a commercial or industrial consumer with an average monthly electricity consumption of $2000 \mathrm{kWh}$ (approximately SGD\$550) is eligible to be contestable while residential consumers are all non-contestable [14].

The electricity prices were separated into contestable and non-contestable due to different pricing in electricity purchase. Contestable consumers are able to purchase from the electricity market using wholesale pricing run by Energy Market Company while non-contestable consumers use the regulated tariff prices from SP Services.

Table 1 data shows the total power harvested from renewable energy in Singapore. Table 2 shows the data taken from Energy Market Authority of Singapore [15]. Table 3 shows the data of the total electricity in the period, day, and year. Table 4 shows the electricity price for a contestable consumer in a 48 period (24 hours) format from Energy Market Company (EMC) for 1st September 2015 [16]. The non-contestable consumer's electricity pricing were 20.35 cents per kWh (with effect from 1 Oct. 15 to 31 Dec. 15) regardless of the time periods [17]. These data collected accommodates different electricity pricing which allows economical research on both non-contestable and contestable electricity sources.

$$
\begin{aligned}
& P_{\text {day }}=P_{\text {year }} / 365 \\
& P_{\text {period }}=P_{\text {day }} / 365
\end{aligned}
$$

where, $P_{\text {year }}$ represents the total power consumption in a year, $P_{\text {day }}$ in a day, and $P_{\text {period }}$ in a period.

The average power consumption is scaled down to year, day, and period using the formula 1 and 2 . Due to different periods having different prices, it can be used to calculate how much the consumers were paying per period.

The mathematic equation for renewable energy in Singapore was defined as follow:

$$
\begin{gathered}
P_{\mathrm{SG} \text { Wind/year }}=P_{\mathrm{Wind}} / 39 \\
P_{\mathrm{SG} \mathrm{Tidal} / \text { year }}=P_{\mathrm{SG} \text { Tidal/Period }} * 365 * 24
\end{gathered}
$$


Table 1. Total renewable energy harvest in Singapore.

\begin{tabular}{cc}
\hline Renewable Energy & Power per annum for Singapore (MWh) \\
\hline Wind & 0.26 \\
Tidal & 8.76 \\
Solar & 4800 \\
Total & 4809.02 \\
\hline
\end{tabular}

Table 2. Singapore electricity data.

\begin{tabular}{cccc}
\hline Year 2014 & Contestable (GWh) & $\begin{array}{c}\text { Non-Contestable } \\
\text { Consumers }(\mathrm{GWh})\end{array}$ & $\begin{array}{c}\text { Total Singapore electricity } \\
\text { demand (GWh) }\end{array}$ \\
\hline Industrial & $18,528.20$ & 1260.30 & $19,788.50$ \\
Commercial & $12,163.50$ & 4790.80 & $16,954.30$ \\
Transport & $2,284.00$ & 155.4 & 2439.40 \\
Residential & 0 & 6935.80 & 6935.80 \\
Others & 28.5 & 256.4 & 284.90 \\
Overall & $33,004.20$ & $13,398.70$ & $46,402.90$ \\
\hline
\end{tabular}

Table 3. Different type of power in period, day, and year.

\begin{tabular}{ccccccc}
\hline \multirow{2}{*}{ Year 2014 } & \multicolumn{3}{c}{ Contestable Consumer } & \multicolumn{2}{c}{ Non-Contestable Consumers } \\
\cline { 2 - 7 } & $\begin{array}{c}\text { Per year } \\
(\mathrm{GWh})\end{array}$ & $\begin{array}{c}\text { Per day } \\
(\mathrm{GWh})\end{array}$ & $\begin{array}{c}\text { Per period } \\
(\mathrm{GWh})\end{array}$ & $\begin{array}{c}\text { Per year } \\
(\mathrm{GWh})\end{array}$ & $\begin{array}{c}\text { Per day } \\
(\mathrm{GWh})\end{array}$ & $\begin{array}{c}\text { Per period } \\
(\mathrm{GWh})\end{array}$ \\
\hline Industrial & $18,528.20$ & 50.76 & 1.06 & 1260.30 & 3.45 & 0.07 \\
Commercial & $12,163.50$ & 33.32 & 0.69 & 4790.80 & 13.13 & 0.27 \\
Transport & 2284.00 & 6.26 & 0.13 & 155.40 & 0.43 & 0.01 \\
Residential & 0.00 & 0.00 & 0.00 & 6935.80 & 19.00 & 0.40 \\
Others & 28.50 & 0.08 & 0.00 & 256.40 & 0.70 & 0.01 \\
Overall & $33,004.20$ & 90.42 & 1.88 & $13,398.70$ & 36.71 & 0.76 \\
\hline
\end{tabular}

where $P_{\text {Wind }}$ represents the total wind power generated for the region for the year, $P_{\mathrm{SG} \text { Wind/year }}$ represents the wind power generated for a year in Singapore. $P_{\mathrm{SG} \mathrm{Tidal} P \text { eriod }}$ represents the tidal power generated for a period in Singapore, $P_{\mathrm{SG} \mathrm{Tidalyear}}$ represents the tidal power generated for a year in Singapore.

In Singapore, the government agencies JTC Corp and the Housing Board are looking into the use of wind turbines. Small and medium-sized enterprises (SMEs) like CygnusPower and Daily Life Renewable Energy (DLRE) are exploring the usage of wind turbines to have better efficiency. Daily Life Renewable Energy (DLRE) had already built a $10 \mathrm{MW}$ commercial wind farm in Sri Lanka to serve 39 countries in the Asia-Pacific region [18]. Thus the power distribution divided equally using formula 3.

There had been a study that Singapore environment can extract 250 MW peak with a tidal barrage [19]. Thus, a team from Nanyang Technological University 
Table 4. Wholesale pricing for 48 periods.

\begin{tabular}{cccccc}
\hline Time & Period & WEP (\$/MWh) & Time & Period & WEP (\$/MWh) \\
\hline 00:00-00:30 & 1 & 77.78 & $12: 00-12: 30$ & 25 & 64.45 \\
00:30-01:00 & 2 & 73.95 & $12: 30-13: 00$ & 26 & 66.39 \\
01:00-01:30 & 3 & 67.14 & $13: 00-13: 30$ & 27 & 71.31 \\
01:30-02:00 & 4 & 68.26 & $13: 30-14: 00$ & 28 & 77.6 \\
02:00-02:30 & 5 & 66.54 & $14: 00-14: 30$ & 29 & 77.73 \\
02:30-03:00 & 6 & 73.85 & $14: 30-15: 00$ & 30 & 85.31 \\
03:00-03:30 & 7 & 69.11 & $15: 00-15: 30$ & 31 & 85.24 \\
03:30-04:00 & 8 & 67.44 & $15: 30-16: 00$ & 32 & 73.11 \\
04:00-04:30 & 9 & 66.06 & $16: 00-16: 30$ & 33 & 67.09 \\
04:30-05:00 & 10 & 60.81 & $16: 30-17: 00$ & 34 & 66.28 \\
05:00-05:30 & 11 & 55.66 & $17: 00-17: 30$ & 35 & 64.35 \\
05:30-06:00 & 12 & 67.75 & $17: 30-18: 00$ & 36 & 60.83 \\
06:00-06:30 & 13 & 68.65 & $18: 00-18: 30$ & 37 & 59.85 \\
06:30-07:00 & 14 & 66.98 & $18: 30-19: 00$ & 38 & 61.1 \\
07:00-07:30 & 15 & 53.95 & $19: 00-19: 30$ & 39 & 65.36 \\
07:30-08:00 & 16 & 56.69 & $19: 30-20: 00$ & 40 & 66.49 \\
08:00-08:30 & 17 & 59.87 & $20: 00-20: 30$ & 41 & 66.91 \\
08:30-09:00 & 18 & 61.41 & $20: 30-21: 00$ & 42 & 61.16 \\
09:00-09:30 & 19 & 61.12 & $21: 00-21: 30$ & 43 & 63.52 \\
09:30-10:00 & 20 & 64.94 & $21: 30-22: 00$ & 44 & 61.19 \\
10:00-10:30 & 21 & 66.55 & $22: 00-22: 30$ & 45 & 58.09 \\
10:30-11:00 & 22 & 66.71 & $22: 30-23: 00$ & 46 & 56.34 \\
11:00-11:30 & 23 & 66.69 & $23: 00-23: 30$ & 47 & 54.3 \\
11:30-12:00 & 24 & 64.59 & $23: 30-00: 00$ & 48 & 53.01 \\
\hline & & & & & \\
\hline
\end{tabular}

(NTU) designed and built 2 turbines which will extract up to a thousand watts of energy per hour combined. This test project shows the Singapore government support of tidal energy usage [20]. By using formula 4, the Tidal energy for a year in Singapore can be calculated.

Singapore total generations of electricity by PV systems (Solar energy) were estimated to be 4.8 GWh electric energy per annum [21]. Singapore Housing and Development Board (HDB) are currently installing PV systems on residential building rooftops to increase the electricity generation by renewable energy [22]. This information allows a realistic calculated amount of renewable energy produced for the overall power grid in Singapore.

\section{Proposed Smart Grid Distribution Management System}

\subsection{Proposed Algorithm}

Figure 1 shows a general flowchart of the algorithm in regard to the price and electricity distribution. 


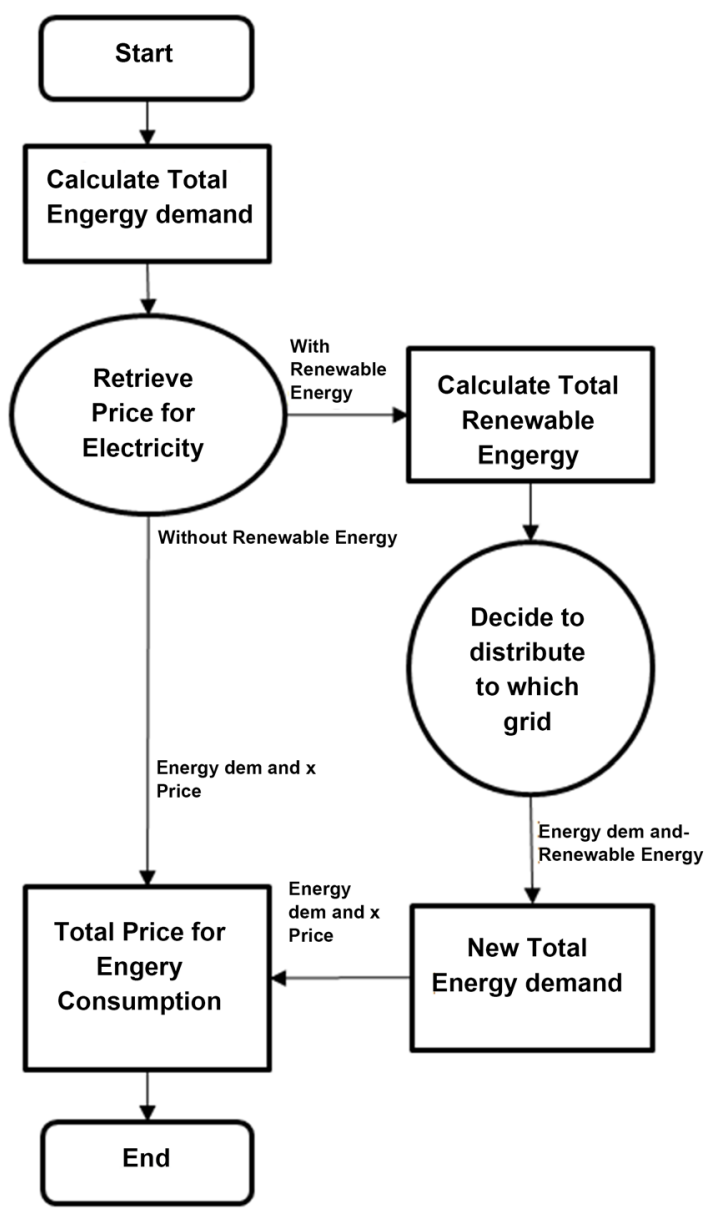

Figure 1. Flowchart for the proposed algorithm.

The mathematical formulas of the cost are defined as follows:

$$
\begin{gathered}
M_{\text {contyr }}=\left(\sum_{i=1}^{48} P_{\text {cont/period }} * P P_{\text {cont }(i)}\right) * 365 \\
M_{\text {non-cont } / \mathrm{yr}}=P_{\text {non-cont } y \text { year }} * P P_{\text {non-cont }} \\
M_{\text {Total/yr }}=M_{\text {cont/year }}+M_{\text {non-cont/year }}
\end{gathered}
$$

where $P P_{\text {cont }(i)}$ represents the price in different period for contestable, $P P_{\text {non-cont }}$ for non-contestable. $M_{\text {contyr }}$ represents the total amount of electricity cost in a year for contestable, $M_{\text {non-contyr }}$ for non-contestable, and $M_{\text {Totalyr }}$ for the total amount of electricity cost. $P_{\text {non-contyear }}$ represents the total power for non-contestable in a year, $P_{\text {cont } / \text { eriod }}$ for contestable in a period.

The equations calculate the consumer cost dependent on how the electricity is being distributed in the grid. These equations are widely used in Singapore to calculate the electricity cost for consumers.

\subsection{Proposed RES Connections}

Figure 2 shows the overall grid connections with RES using Power World Simulator Software [23]. Figure 3 shows the grid connection with power 


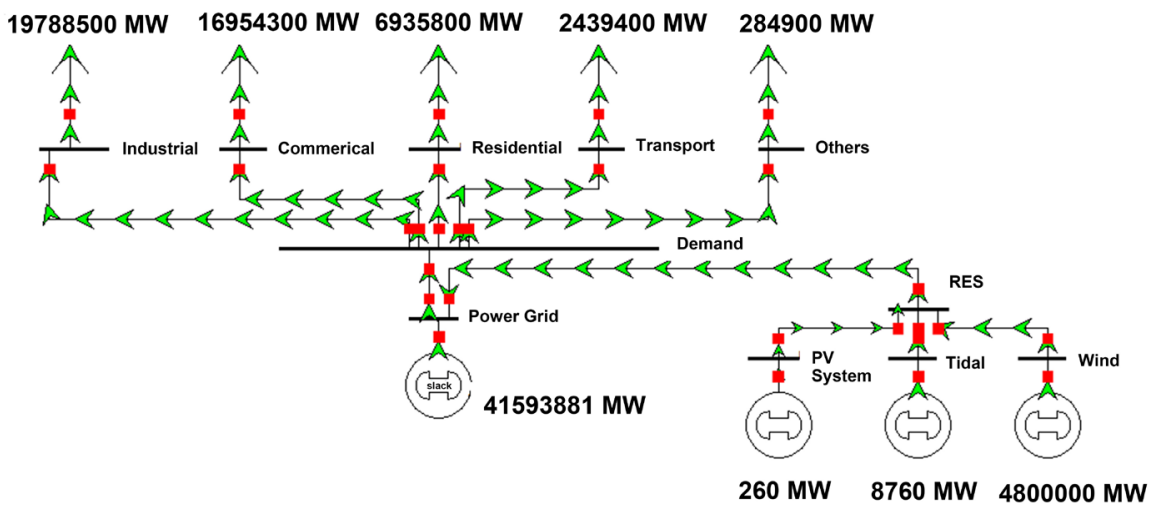

Figure 2. Illustration of overall grid connections.

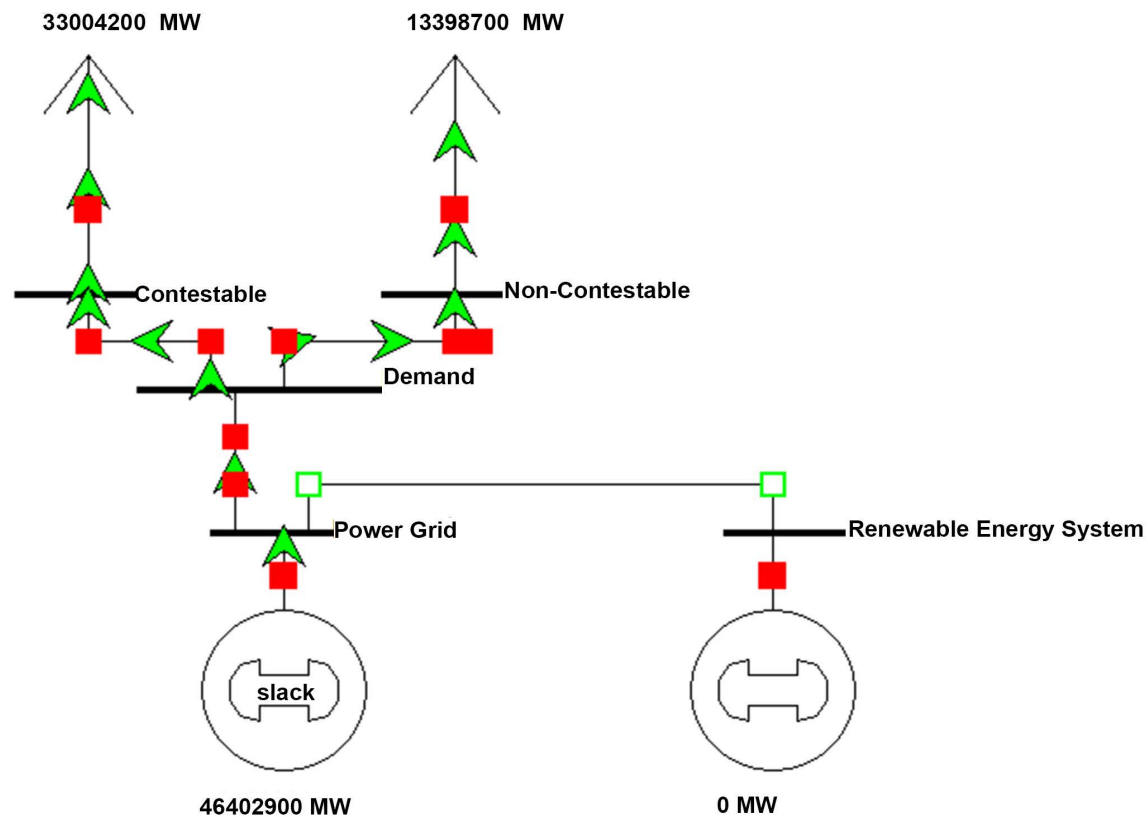

Figure 3. Illustration of PG without RES in PWS.

consumption if no renewable energy is connected. Figure 4 shows the grid connection with power consumption if renewable energy is connected and evenly distributed. Figure 5 shows the grid connection with power consumption if renewable energy is connected and distributed only to contestable. Figure 6 shows the grid connection with power consumption if renewable energy is connected and distributed only to non-contestable.

For this research, Figure 3 will be the first case study, Figure 4 will be the second case study, Figure 5 will be the third, and lastly Figure 6 . These case studies will be used to determine the economic impact of the electricity prices in Singapore.

\subsection{Proposed Multi-Agent System}

Figure 7 depicts the overall picture of the multi-agent system. Smart Grid Distribution Management System (SGDMS) was categorised into two parts 


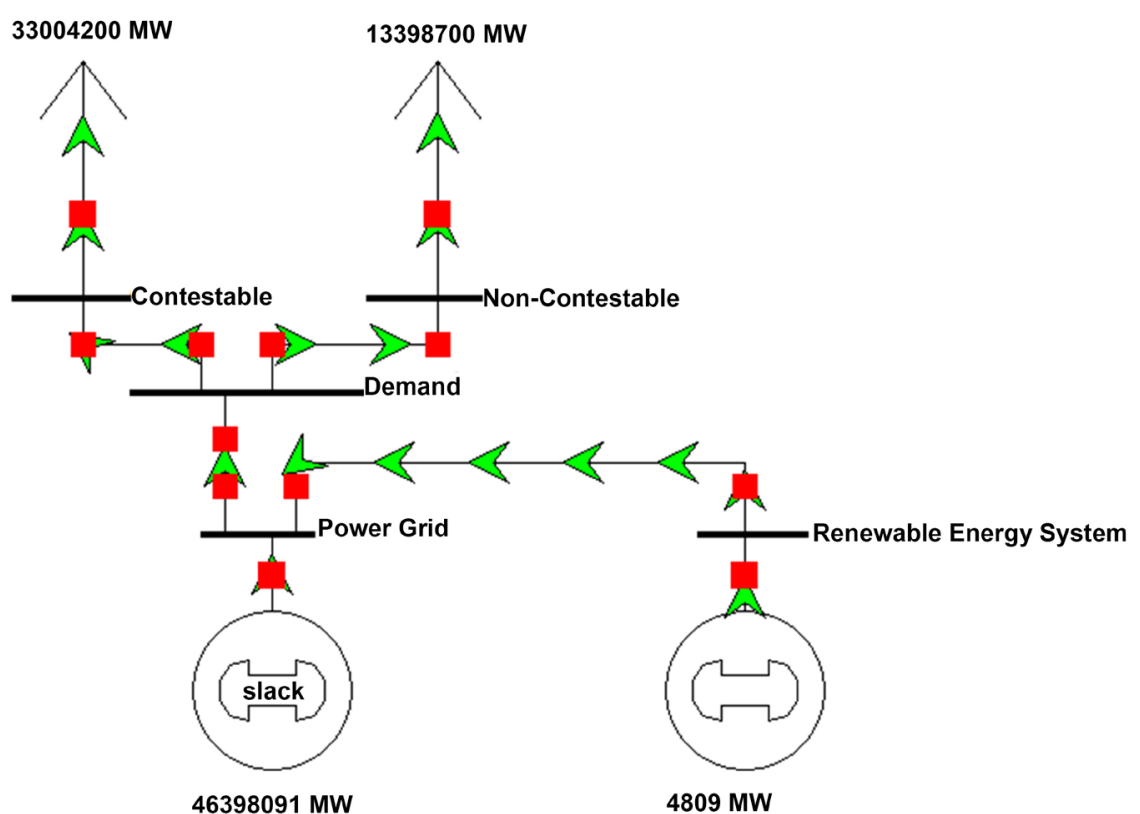

Figure 4. Illustration of PG with RES evenly distributed in PWS.

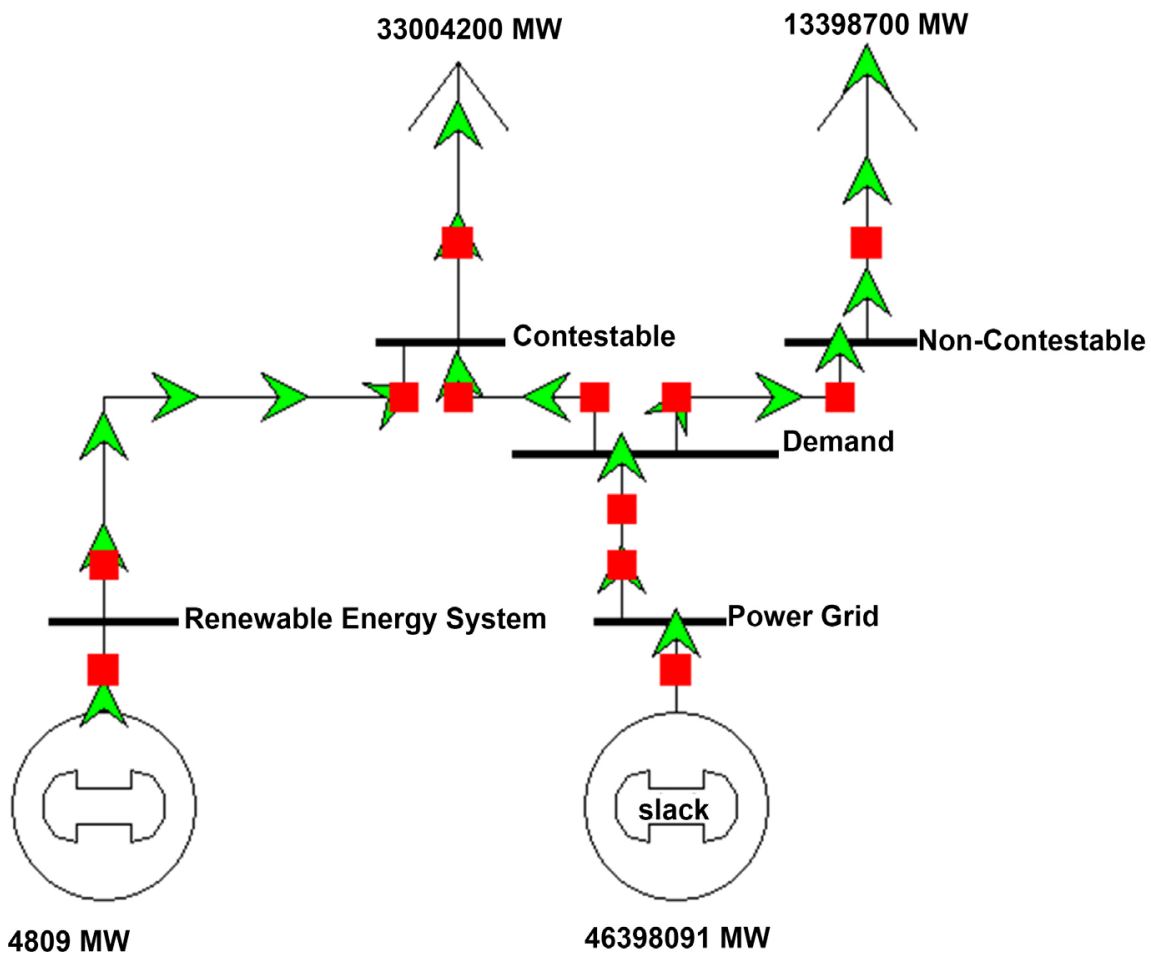

Figure 5. Illustration of PG with RES distribution to contestable in PWS.

which are the Renewable Energy System (RES) and Grid System (GS). RES was then further categorised into three parts which are the PhotoVoltaics (PV) system, Tidal Energy, and Wind Energy. GS was then further categorised into three parts which are the Industrial Grid (IG), Commercial Grid (CG), and Residential Grid (RG). 


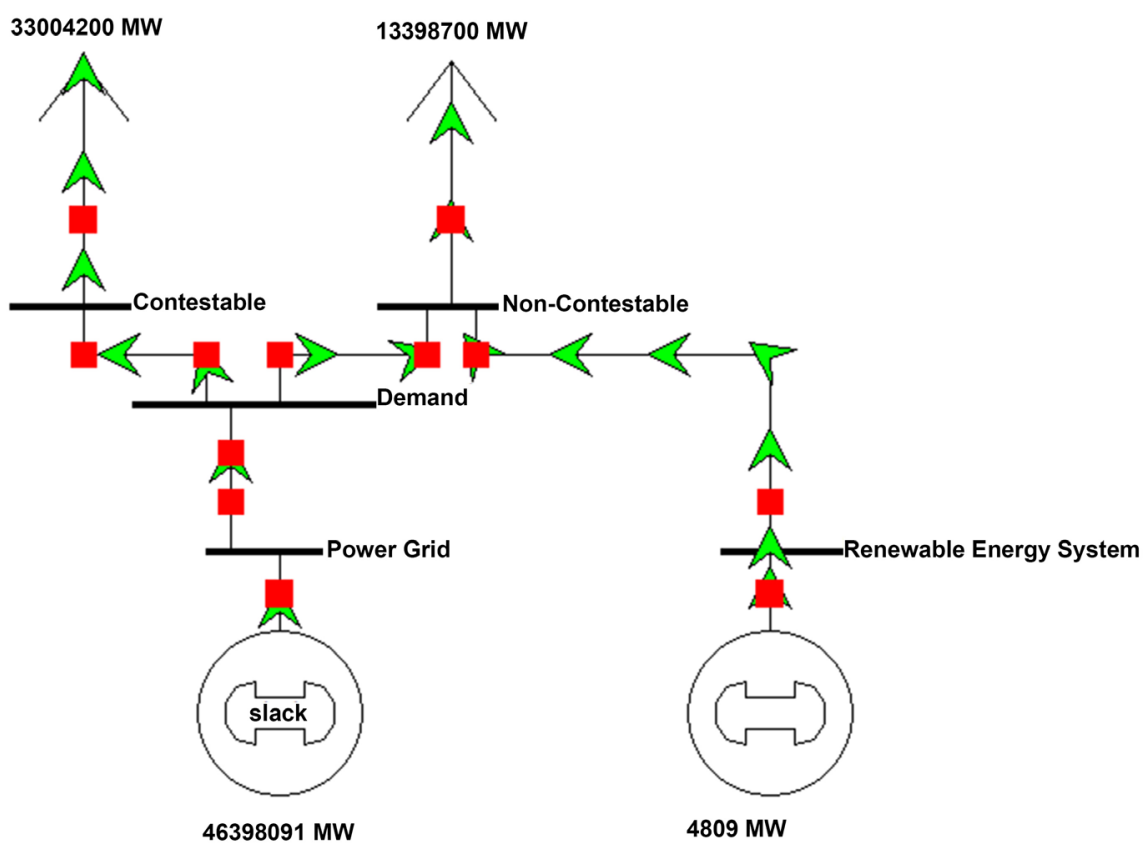

Figure 6. Illustration of PG with RES distribution to non-contestable in PWS.

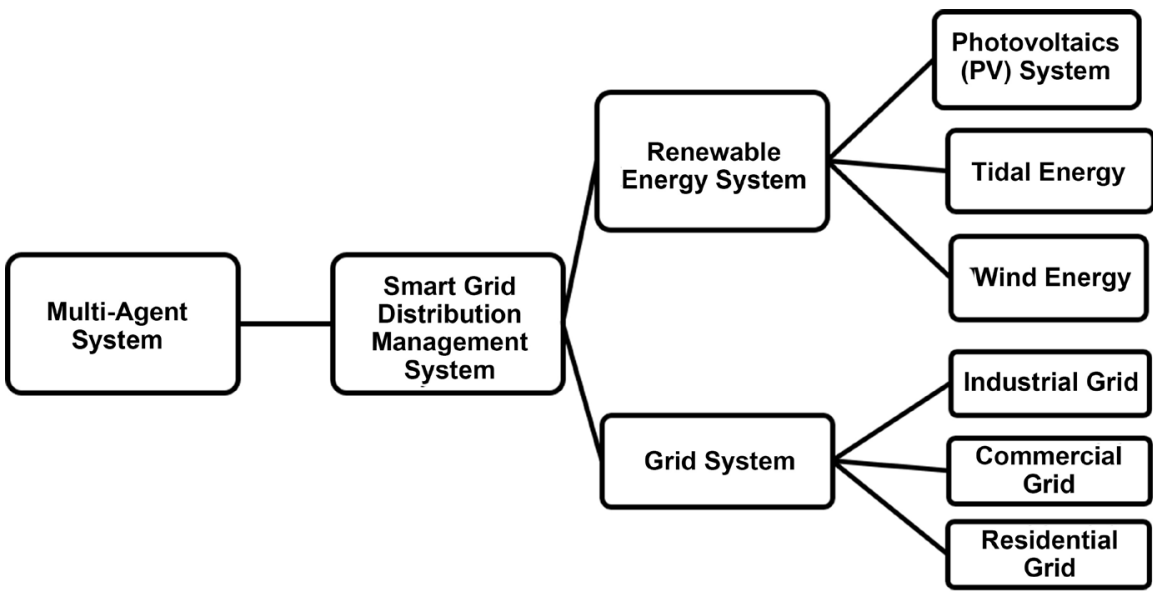

Figure 7. MAS architecture.

The functionality of the RES collects and calculates the data that is available to the SGDMS. GS calculates the amount of electricity that is needed for them. SGDMS will then decide how much power will be distributed to which grid. The messages set are "REQUEST", "SUBSCRIBE", "CONFIRM" ", "INFORM" and "CFP". Each message sent would provide different kinds of information when it is required during the process of algorithm calculations.

\section{Simulation Studies and Results}

Simulation studies were carried out on the following types of the distribution system which are given in Table 5.

Table 6 represents the final simulation results for each individual power distribution system. It shows a significant difference of up to SGD\$978634.84 
Table 5. Representatives of different power distribution system.

\begin{tabular}{cc}
\hline Representative & Description \\
\hline No RES & Power Grid with no RES supply \\
RES & Power Grid with evenly distributed RES supply \\
RES1 & Power Grid with RES supply distributed to contestable only \\
RES2 & Power Grid with RES supply distributed to non-contestable only \\
\hline
\end{tabular}

Table 6. Overall results of electricity distribution to different sectors.

\begin{tabular}{|c|c|c|c|c|}
\hline Description & No RES & RES & RES1 & RES2 \\
\hline \multicolumn{5}{|c|}{ Amount of RES power distribution (MWh) } \\
\hline Contestable & 0 & 2404.51 & 4809.02 & 0 \\
\hline Non-Contestable & 0 & 2404.51 & 0 & 4809.02 \\
\hline \multicolumn{5}{|c|}{ Total Power after RES power distribution (GWh) } \\
\hline Contestable & $33,004.20$ & $33,001.80$ & $32,999.39$ & $33,004.20$ \\
\hline Non-Contestable & $13,398.70$ & $13,396.30$ & $13,398.70$ & $13,393.89$ \\
\hline \multicolumn{5}{|c|}{ Average electricity usage (MWh) } \\
\hline $\begin{array}{l}\text { Contestable for } 1 \\
\text { period }\end{array}$ & 1883.80 & 1883.66 & 1883.53 & 1883.80 \\
\hline \multicolumn{5}{|c|}{ Average electricity price (SGD\$) } \\
\hline $\begin{array}{l}\text { Contestable } \\
\text { for } 1 \text { day }\end{array}$ & $5,951,889.27$ & $5,951,455.64$ & $5,951,022.021$ & $5,951,889.27$ \\
\hline $\begin{array}{l}\text { Contestable } \\
\text { for } 1 \text { year }\end{array}$ & $2,172,439,582$ & $2,172,281,310$ & $2,172,123,038$ & $2,172,439,582$ \\
\hline $\begin{array}{l}\text { Non-Contestable } \\
\text { for } 1 \text { year }\end{array}$ & $2,726,635,450$ & $2,726,146,133$ & $2,726,635,450$ & $2,725,656,815$ \\
\hline \multicolumn{5}{|c|}{ Cost (SGD\$) } \\
\hline Total for 1 year & $4,899,075,032$ & $4,898,427,442$ & $4,898,758,488$ & $4,898,096,397$ \\
\hline $\begin{array}{l}\text { Savings compared } \\
\text { to no RES }\end{array}$ & 0 & $647,589.66$ & $316,544.49$ & $978,634.84$ \\
\hline
\end{tabular}

savings by using the integrated power grid when comparing RES with the traditional power grid.

These results were understood by the amount of money saved when more renewable energy was distributed to the contestable or non-contestable electricity source with the same total electricity consumption. The simulation result shows when more power was distributed to the non-contestable electricity demand, the overall electricity pricing would be cheaper compared to the contestable electricity demand.

The results shown in Figure 8 use Java with the extension of Jade to simulate the overall results and communications of the grids. Figure 9 and Figure 10 shows the result of price per period and the total price of the power grid with or without renewable energy. 


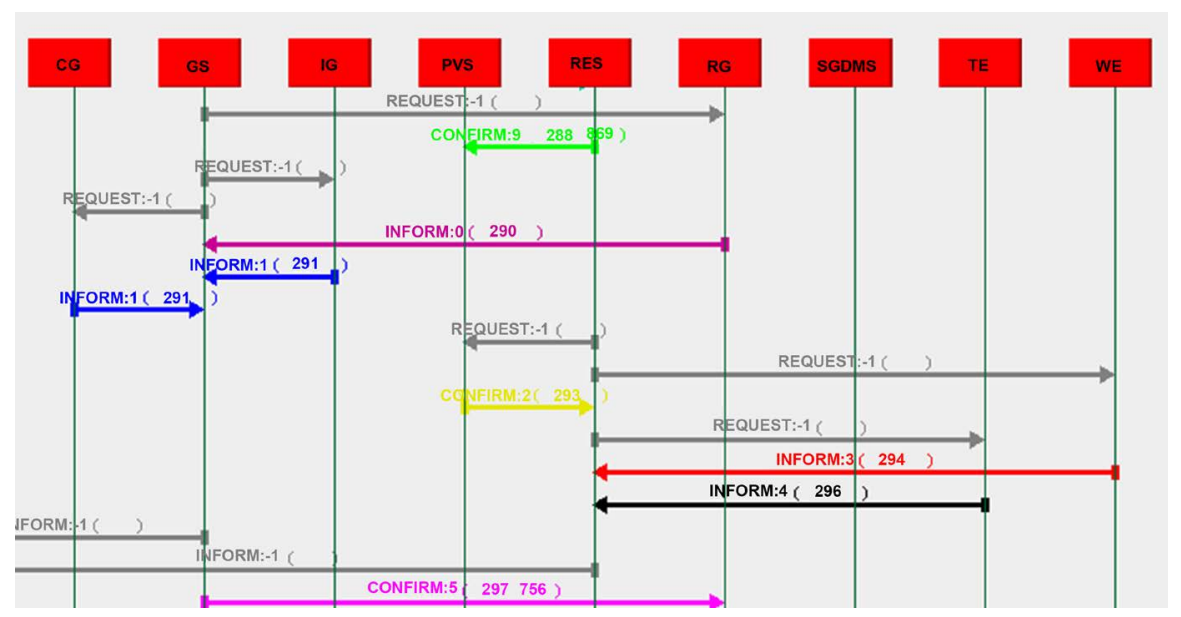

Figure 8. Simulation of MAS communication using JADE.

EMC Price for contestable in half an hour $=\$ 58.09$

Electricity Price for contestable in half an hour $=\$ 109430.02157534247$

TotalC $=\$ 563605.17191781$

Period $=45$

EMC Price for contestable in half an hour $=\$ 56.34$

Electricity Price for contestable in half an hour $=\$ 106133.3691780822$

TotalC $=\$ 5749738.541095892$

Period $=46$

EMC Price for contestable in half an hour $=\$ 54.3$

Electricity Price for contestable in half an hour $=\$ 102290.41438356164$

TotalC $=\$ 5852028.955479453$

\section{Period $=47$}

EMC Price for contestable in half an hour $=\$ 53.01$

Electricity Price for contestable in half an hour $=\$ 99860.31061643835$

TotalC $=\$ 5951889.26609892$

Power for contestable in half an hour $=1883.8013698630136$

TotalC $=\$ 2.1724395821250005 \mathrm{E} 9$

TotalNC $=2.72663545 \mathrm{Eg}$

TotalPrice for a year $=4.899075032125 \mathrm{E} 9$

Figure 9. Simulation of prices for period and year without RES.

These simulations show the effects of economic impacts on the distribution of renewable energy to different sectors.

\section{Conclusions}

In this paper, it was shown how the use of renewable energy sources makes differences in Singapore power grid. The proposed algorithm optimises the electricity cost of consumers while maximizing the use of renewable energy sources. These simulation studies show that the proposed Smart Grid Distribution Management System (SGDMS) achieves the maximum use of 


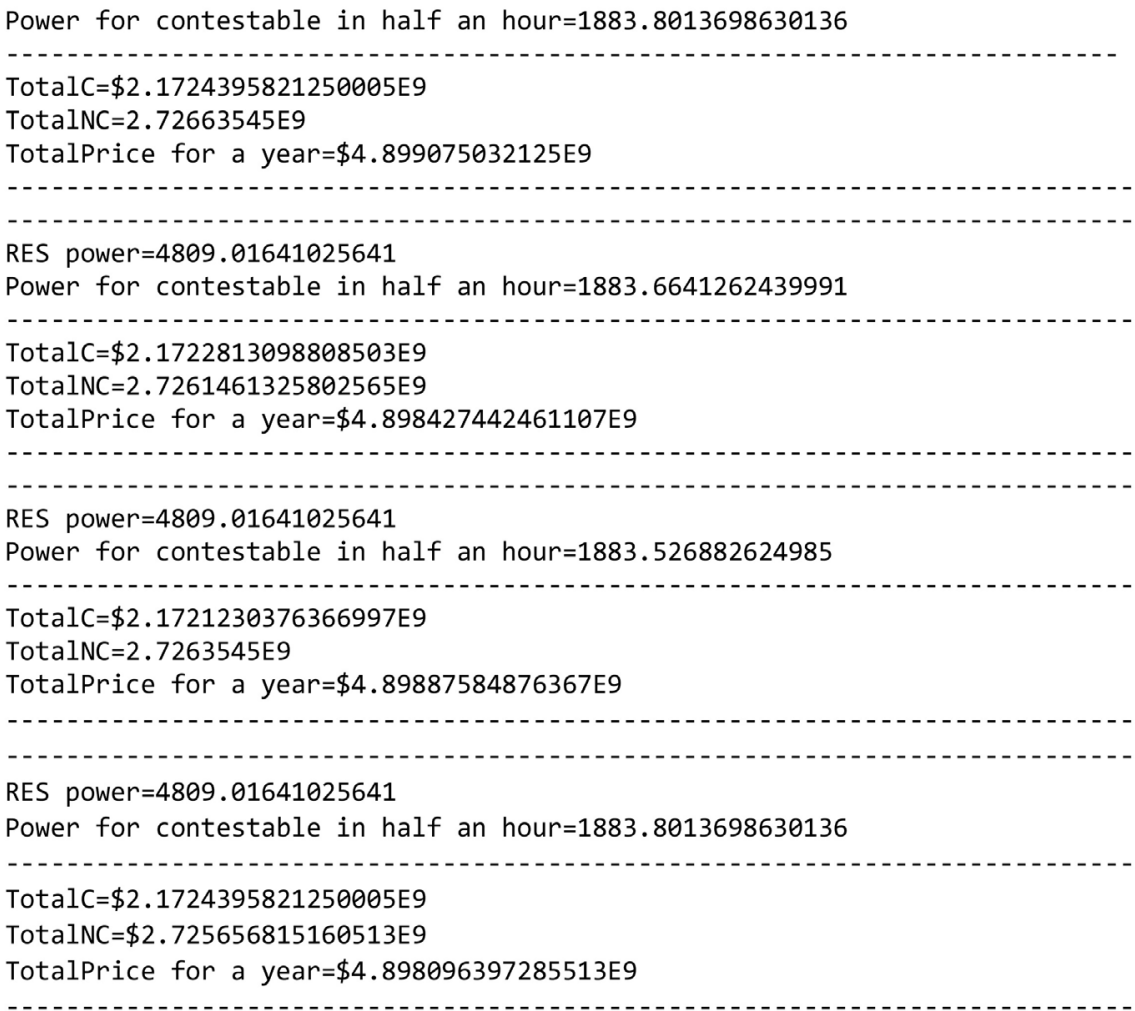

Figure 10. Simulation of prices for period and year results.

power distribution, minimises the cost of electricity bills and lowers greenhouse effects by the existing power grid.

In the view of the smart grid, this research demonstrates various types of power grid distribution and the impact on the prices based on the current electricity market. These lead to a smart nation concept which would be beneficial to the future of Singapore.

Enhancements of the SGDMS would require an increase in reliability and further improvements for optimization in order to get better efficiency of the grid. With the help of increased renewable energy sources, overloading of generators will be greatly reduced. Ultimately, this approach will step towards a more environmentally friendly and cost-effective grid system for Singapore.

\section{Conflicts of Interest}

The authors declare no conflicts of interest regarding the publication of this paper.

\section{References}

[1] Li, W., Logenthiran, T., Woo, W., Phan, V. and Srinivasan, D. (2016) Implementation of Demand Side Management of a Smart Home Using Multi-Agent System. IEEE World Congress on Computational Intelligence, Vancouver, BC, 24-29 July 2016, 1-8.

[2] McArthur, S.D., Davidson, E.M., Catterson, V.M., Dimeas, A.L., Hatziargyriou, 
N.D., Ponci, F. and Funabashi, T. (2007) Multi-Agent Systems for Power Engineering Applications Part I: Concepts, Approaches, and Technical Challenges. IEEE Transactions on Power Systems, 22, 1743-1752.

[3] McArthur, S.D., Davidson, E.M., Catterson, V.M., Dimeas, A.L., Hatziargyriou, N.D., Ponci, F. and Funabashi, T. (2007) Multi-Agent Systems for Power Engineering Applications Part II: Technologies, Standards, and Tools for Building Multi-Agent Systems. IEEE Transactions on Power Systems, 22, 1753-1759.

[4] Zhang, D., Li, S., Sun, M. and Neill, Z.O. (2016) An Optimal and Learning-Based Demand Response and Home Energy Management System. IEEE Transactions on Smart Grid, 7, 1790-1801. https://doi.org/10.1109/TSG.2016.2552169

[5] Li, W., Logenthiran, T. and Woo, W. (2015) Intelligent Multi-Agent System for Smart Home Energy Management. IEEE Innovative Smart Grid Technologies-Asia (ISGT ASIA), Bangkok, 3-6 November 2015, 1-6.

[6] Li, W., Logenthiran, T., Phan, V.-T. and Woo, W.L. (2017) Housing Development Building Management System (HDBMS) for Optimized Electricity Bills. Transactions on Environment and Electrical Engineering, 2, 64-71.

https://doi.org/10.22149/teee.v2i2.113

[7] Li, W., Logenthiran, T., Phan, V.-T. and Woo, W.L. (2017) Intelligent Housing Development Building Management System (HDBMS) for Optimized Electricity Bills. IEEE International Conference on Environment and Electrical Engineering, IEEE Industrial and Commercial Power Systems Europe (EEEICI I \& CPS Europe), Milan, 6-9 June 2017, 1-6.

[8] Chao, H.-L., Tsai, C.-C., Hsiung, P.-A., Chou, I., et al. (2014) Smart Grid as a Service: A Discussion on Design Issues. The Scientific World Journal, 2014, Article ID: 535308.

[9] Corno, F. and Razzak, F. (2012) Intelligent Energy Optimization for User Intelligible Goals in Smart Home Environments. IEEE Transactions on Smart Grid, 3, 2128-2135. https://doi.org/10.1109/TSG.2012.2214407

[10] Wang, C., Zhou, Y., Jiao, B., Wang, Y., Liu, W. and Wang, D. (2015) Robust Optimization for Load Scheduling of a Smart Home with Photovoltaic System. Energy Conversion and Management, 102, 247-257. https://doi.org/10.1016/j.enconman.2015.01.053

[11] Ng, C., Logenthiran, T. and Woo, W. (2015) Intelligent Distributed Smart Grid Network Reconfiguration. Innovative Smart Grid Technologies-Asia (ISGT ASIA), Bangkok, 3-6 November 2015, 1-6.

[12] Li, W., Logenthiran, T., Phan, V.-T. and Woo, W.L. (2016) Intelligent Multi-Agent System for Power Grid Communication. IEEE Region 10 Conference (TENCON), Singapore, 22-25 November 2016, 3386-3389.

[13] Authority, E.M. (2015) Energy Consumption. https://www.ema.gov.sg/cmsmedia/Publications_and_Statistics/Publications/ses/20 16/energy-consumption/index.html

[14] Market, O.E. (2018) Singapore's Electricity Market. https://www.openelectricitymarket.sg/about/market-overview.html

[15] Authority, E.M. (2015) Singapore Energy Statistics. https://www.ema.gov.sg/cmsmedia/Publications_and_Statistics/Publications/SES\%2 02015\%20Chapters/Publication_Singapore_Energy_Statistics_2015.pdf

[16] Company, E.M. (2015) Price information. https://www.emcsg.com/marketdata/priceinformation\#priceDataView 
[17] S. P. Ltd. (2014) Tari_s. http://www.singaporepower.com.sg/irj/servlet/prt/portal/prtroot

[18] Cheam, J. (2011) The Straits Times: Singapore Rides on Asia’s Wind Market. https://www.nccs.gov.sg/news/straits-times-singapore-rides-asias-wind-market

[19] Srikanth, N. (2014) Barriers to Ocean Energy Technology Adoption and Role of Policies \& Institutional System to Promote in Asia.

http://www.icoe2014canada.org/wp-content/uploads/2014/11/3-Srikanth-Halifax-p resentation-v10.pdf

[20] Ee, D. (2011) Singapore's First Tidal Energy Generator Launched off Sentosa. https://www.straitstimes.com/singapore/singapores-first-tidal-energy-generator-lau nched-off-sentosa

[21] J. L., et al. (2011) Solar Energy Technology Primer: A Summary.

[22] Tanoto, B. (2017) Hdb Calls "Largest Tender" to Install Solar Panels across Government Agencies.

https://www.channelnewsasia.com/news/singapore/hdb-calls-largest-tender-to-inst all-solar-panels-across-9365000

[23] P. Corporation. The Visual Approach to Electric Power Systems. https://www.powerworld.com/ 